\title{
Free Vibration of FGSW Plates Partially Supported by Pasternak Foundation Based on Refined Shear Deformation Theories
}

\author{
Cong Ich Le, ${ }^{1}$ Vu Nam Pham, ${ }^{2,3}$ and Dinh Kien Nguyen (iD ${ }^{3,4}$ \\ ${ }^{1}$ Le Quy Don Technical University, 236 Hoang Quoc Viet, Hanoi, Vietnam \\ ${ }^{2}$ Thuyloi University, 175 Tay Son, Dong Da, Hanoi, Vietnam \\ ${ }^{3}$ Graduate University of Science and Technology, VAST, 18 Hoang Quoc Viet, Hanoi, Vietnam \\ ${ }^{4}$ Institute of Mechanics, VAST, 18 Hoang Quoc Viet, Hanoi, Vietnam \\ Correspondence should be addressed to Dinh Kien Nguyen; ndkien@imech.vast.vn
}

Received 21 February 2020; Accepted 7 March 2020; Published 7 April 2020

Academic Editor: Marek Lefik

Copyright ( $\odot 2020$ Cong Ich Le et al. This is an open access article distributed under the Creative Commons Attribution License, which permits unrestricted use, distribution, and reproduction in any medium, provided the original work is properly cited.

\begin{abstract}
A refined third-order shear deformation theory (RTSDT), in which the transverse displacement is split into bending and shear parts, is employed to formulate a four-node quadrilateral finite element for free vibration analysis of functionally graded sandwich (FGSW) plates partially supported by a Pasternak foundation. An element based on the refined first-order shear deformation theory (RFSDT) which requires a shear correction factor is also derived for comparison purpose. The plates consist of a fully ceramic core and two functionally graded skin layers with material properties varying in the thickness direction by a power gradation law. The Mori-Tanaka scheme is employed to evaluate the effective moduli. The elements are derived using Lagrangian and Hermitian polynomials to interpolate the in-plane and transverse displacements, respectively. The numerical result reveals that the frequencies obtained by the RTSDT element are slightly higher than the ones using the RFSDT element. It is also shown that the foundation supporting area plays an important role on the vibration of the plates, and the effect of the material distribution on the frequencies is dependent on this parameter. A parametric study is carried out to highlight the effects of the material inhomogeneity, the foundation stiffness parameters, and the foundation supporting area on the frequencies and vibration modes. The influence of the layer thickness and aspect ratios on the frequencies is also examined and highlighted.
\end{abstract}

\section{Introduction}

With the development of advanced manufacturing methods [1], functionally graded materials (FGMs) - a new type of composite materials initiated by Japanese researchers in mid-1980 [2], can be incorporated into sandwich construction to improve performance of the structures. Functionally graded sandwich (FGSW) structures can be designed to have a smooth variation of properties, which helps to avoid the interface separation problem as often seen in the conventional sandwich structures. Investigations on mechanical behaviour of FGSW structures have been intensively reported in recent years, and contributions that are most relevant to present work are discussed below.

Zenkour [3,4] presented a sinusoidal shear deformation plate theory for bending, buckling, and vibration analyses of sandwich plates with a homogeneous ceramic core and two FGM faces. Parametric studies carried out by the author show the importance of the material distribution, aspect ratio, and core thickness on the mechanical behaviour of the plates. The theory was then employed in [5] to study the thermal buckling of FGSW plates. Xiang et al. [6] calculated frequencies of sandwich plates with homogeneous core and FGM face sheets using the $n$ th-order shear deformation theory and the meshless global collocation method. Neves et al. [7] presented a quasi-3D shear deformation theory for analyzing isotropic and FGSW plates, taking the extensibility in the thickness direction into account. The collocation with radial basis functions was adopted by the authors to obtain the static, buckling, and free vibration characteristics. The bending, buckling, and free vibration of FGSW plates were also considered by Thai et al. [8] using a first-order shear 
deformation theory. The shear stresses in the theory are directly computed from transverse shear forces, and a shear correction factor is not necessary to use. Iurlaro et al. [9] adopted the refined zigzag theory to formulate the finite element formulations for bending and free vibration analysis of FGSW plates. The numerical investigations by the authors showed that the zigzag theory is superior in predicting the mechanical behavior of the plates to the first-order and third-order shear deformation theories. In [10], Pandey and Pradyumna employed the higher-order layerwise theory to derive an eight-node isoparametric element for static and dynamic analyses of FGSW plates. The efficiency and accuracy of the derived element in evaluating the bending and dynamic characteristics of the plates are shown through the numerical investigation. Free vibration analysis of FGSW plate was carried out by Belabed et al. [11] using a hyperbolic plate theory. The effect of porosities on bending of sandwich plate with a homogeneous core and FGM skin layers was considered by Daikh and Zenkour [12] using a high-order shear deformation theory. Based on a quasi-3D shear deformation theory, Mahmoudi et al. [13] presented an analytical method for thermomechanical bending analysis of FGSW plates resting on a Pasternak foundation. Navier's solution was employed by the authors to solve the governing equations, and the effect of thermal loads and foundation stiffness on the bending behaviour of the plates was examined in detail.

A shear deformation theory is necessary to employ in analyzing composite plates since the shear deformation is important in mechanical behaviour of the plates. In addition to the well-known plate theories [14-16], a number of shear deformation theories have been proposed in the last two decades. Several authors kept the transverse displacement unchanged as in the above theories and tried to modify the in-plane displacements [16-22]. On the other hand, the transverse displacement in some newly proposed theories is modified by adding some terms to account for a variation in the plate thickness. Ghugal and Sayyad [23] proposed sixunknown plate theories by adding trigonometric terms to the displacements of Kirchhoff theory. Nine-unknown sinusoidal and hyperbolic plate theories with the transverse displacement quadratically varying in the thickness were proposed by Neves et al. [24, 25], respectively. Zenkour $[26,27]$ used the trigonometric and hyperbolic functions to modify the displacement field to form the four-unknown shear deformation theories for bending analysis of FGM plates. Some authors refined the plate theories by splitting the transverse displacement into bending and shear parts. In this line of works, Shimpi and Patel [28] and Thai and Kim [29] proposed third-order shear deformation theories for free vibration and bending analyses of plates. The theories have only four unknowns which could improve computational efficiency. A first-order shear deformation theory which can be considered as a special case of the third-order theory in [28] has been recommended by Shimpi et al. [30]. The theory is very simple, but it needs shear correction factors to correct the discrepancy between the actual parabolic transverse shear stress distribution and the computed one. Thai and Vo [31], Meiche et al. [32], and Daouadji et al.
[33] also split the transverse displacement into bending and shear parts, but used trigonometric and hyperbolic functions to modify the in-plane displacements in their four-unknown plate theories. Bessaim et al. [34] proposed a five-unknown theory by adding hyperbolic functions to the transverse displacements to account for the thickness variation of this displacement. Zaoui et al. [35] established the two-dimensional and quasi-3D theories for modeling the free vibration of FGM plates on Pasternak foundation. The theories employed a shear strain shape function which enables to take both the transverse shear and thickness stretching effects into account.

Among the above discussed shear deformation theories, the four-unknown refined theories proposed by Shimpi and his co-workers in $[28,30]$ are simple, and they are employed herein to study free vibration of FGSW plates on a Pasternak foundation. In addition, it has been shown that the method of analysis and the behaviour of structures partially supported by a foundation are much different from that of the ones fully supported by the foundation $[36,37]$. The objectives of the present paper are two-fold. One is to derive finite element formulations for evaluating vibration characteristics of FGSW plates partially supported by Pasternak foundation, which to the authors' best knowledge has not been reported in the literature. The other is to study how the plate frequencies obtained by finite elements based on the newly proposed first-order and third-order shear deformation theories are different. The plates considered herein consist of three layers, a pure ceramic core and two functionally graded skin layers with material properties varying the thickness direction by a power gradation law. The finite elements considered in the present work are four-node quadrilateral elements, and they are derived by using Lagrange and Hermite polynomials to interpolate the in-plane and transverse displacements, respectively. Parametric studies are carried out to highlight the effects of the material distribution and the foundation support on the vibration characteristics of the plates.

\section{Problem Formulation}

2.1. FGSW Plate on Foundation. A rectangular FGSW plate with length $a$, width $b$, and thickness $h$, partially supported by a Pasternak foundation as depicted in Figure 1, is considered. The plate consists of three layers, a homogeneous ceramic core and two metal-ceramic FGM skin layers. In Figure 1 , the $(x, y)$ plane is coincident with the midplane, and $z_{0}=-h / 2, z_{1}, z_{2}$, and $z_{3}=h / 2$ are, respectively, the vertical coordinates of the bottom surface, the two layer interfaces, and the top surface. The foundation is the Pasternak type, and it is represented by Winkler springs of stiffness $k_{W}$ and a shear layer with stiffness $k_{G}$. The foundation is assumed to support the plate on a rectangular area $\left(a_{f}, b_{f}\right)$ at the lower left corner, as shown in Figure 1. The volume fractions of the ceramic $V_{c}^{(k)}$ and metal $V_{m}^{(k)}(k=1, \ldots, 3)$ are considered to vary in the plate thickness according to 

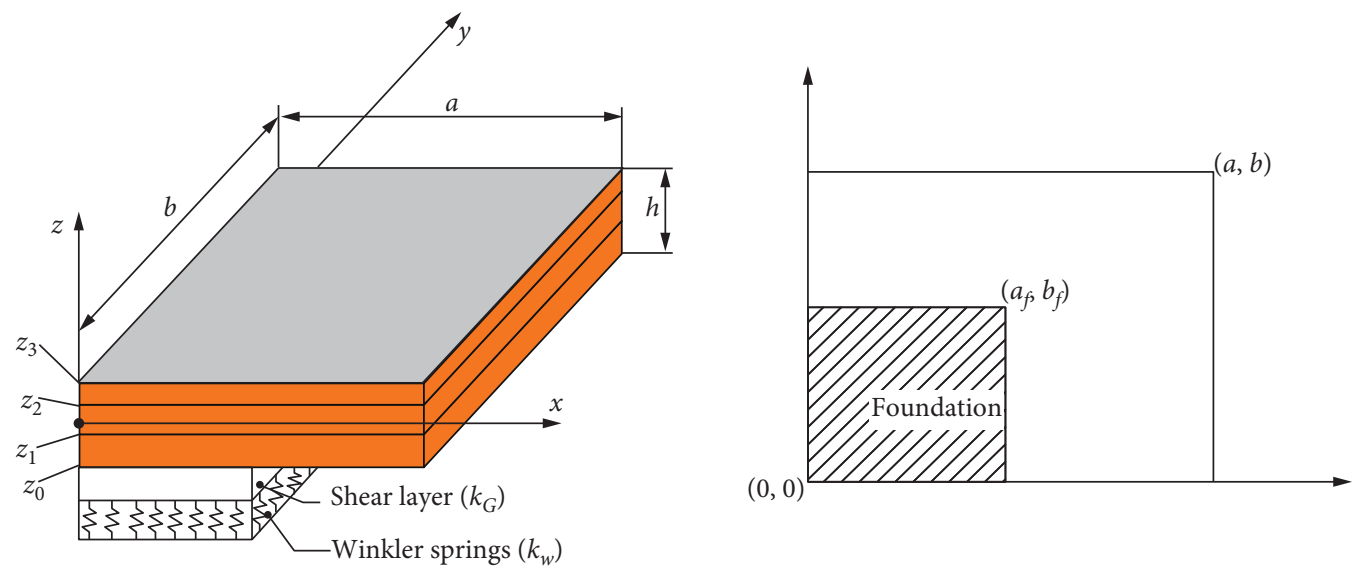

FIGURe 1: An FGSW plate partially supported by a Pasternak foundation.

$$
\begin{cases}V_{c}^{(1)}(z)=\left(\frac{z-z_{0}}{z_{1}-z_{0}}\right)^{n}, & \text { for } \quad z \in\left[z_{0}, z_{1}\right], \\ V_{c}^{(2)}(z)=1, & \text { for } z \in\left[z_{1}, z_{2}\right], \\ V_{c}^{(3)}(z)=\left(\frac{z-z_{3}}{z_{2}-z_{3}}\right)^{n}, & \text { for } \quad z \in\left[z_{2}, z_{3}\right], \quad \text { and } V_{m}^{(k)}=1-V_{c}^{(k)},\end{cases}
$$

where $n(0 \leq n \leq \infty)$ is the material grading index. The subscripts ' $c$ ' and ' $m$ ' in equation (1) and hereafter stand for "ceramic" and "metal," respectively.

The Mori-Tanaka scheme [38] is employed herewith to evaluate the effective properties of the FGM layers. According to the Mori-Tanaka scheme, the effective bulk modulus $K_{f}^{(k)}$ and shear modulus $G_{f}^{(k)}$ of the $k$ th layer of the plate are given by

$$
\begin{aligned}
& \frac{K_{f}^{(k)}-K_{m}}{K_{c}-K_{m}}=\frac{V_{c}^{(k)}}{1+\left(1-V_{c}^{(k)}\right)\left(K_{c}-K_{m}\right) /\left(K_{m}+4 G_{m} / 3\right)}, \\
& \frac{G_{f}^{(k)}-G_{m}}{G_{c}-G_{m}}=\frac{V_{c}^{(k)}}{1+\left(1-V_{c}^{(k)}\right)\left(G_{c}-G_{m}\right) / G_{m}+G_{m}\left(9 K_{m}+8 G_{m}\right) /\left(6 K_{m}+12 G_{m}\right)},
\end{aligned}
$$

where $K_{c}, G_{c}, K_{m}$, and $G_{m}$ are the bulk and shear moduli of ceramic and metal, respectively.

The effective Young's modulus $E_{f}^{(k)}$ and Poisson's ratio $v_{f}^{(k)}$ are calculated via the bulk and shear moduli as

$$
\begin{aligned}
& E_{f}^{(k)}=\frac{9 K_{f}^{(k)} G_{f}^{(k)}}{3 K_{f}^{(k)}+G_{f}^{(k)}}, \\
& v_{f}^{(k)}=\frac{3 K_{f}^{(k)}-2 G_{f}^{(k)}}{6 K_{f}^{(k)}+2 G_{f}^{(k)}} .
\end{aligned}
$$

The effective mass density of the $k$ th layer $\rho_{f}^{(k)}$ evaluated by Voigt's model is of the form

$$
\rho_{f}^{(k)}=\left(\rho_{c}-\rho_{m}\right) V_{c}^{(k)}+\rho_{m}
$$

where $\rho_{c}$ and $\rho_{m}$ are the mass density of the ceramic and metal, respectively.

2.2. Refined Shear Deformation Theories. In the refined third-order shear deformation theory (RTSDT) of Shimpi and Patel [28], the transverse displacement is split into bending and shear parts, $w_{b}$ and $w_{s}$, and the displacements of a point in $x, y$, and $z$ directions, $u(x, y, z, t), v(x, y, z, t)$, and $w(x, y, t)$, respectively, are given by

$$
\begin{aligned}
u(x, y, z, t) & =u_{0}(x, y, t)-z w_{b, x}(x, y, t)-f(z) w_{s, x}(x, y, t), \\
v(x, y, z, t) & =v_{0}(x, y, t)-z w_{b, y}(x, y, t)-f(z) w_{s, y}(x, y, t), \\
w(x, y, t) & =w_{b}(x, y, t)+w_{s}(x, y, t)
\end{aligned}
$$

where $u_{0}(x, y, t)$ and $v_{0}(x, y, t)$ are the in-plane displacements of a point on the $(x, y)$ plane, and

$$
f(z)=z\left[-\frac{1}{4}+\frac{5}{3}\left(\frac{z}{h}\right)^{2}\right] \text {. }
$$

In equation (5) and hereafter, a subscript comma is used to denote the derivative with respect to the variable that follows. When $f(z)=0$, equation (5) results in the displacement field of the refined first-order shear deformation theory (RFSDT) proposed by Shimpi et al. in [30].

The strains resulted from equation (5) are of the forms 


$$
\begin{aligned}
& \left\{\begin{array}{c}
\varepsilon_{x} \\
\varepsilon_{y} \\
\gamma_{x y}
\end{array}\right\}=\left\{\begin{array}{c}
u_{0, x} \\
v_{0, y} \\
u_{0, y}+v_{0, x}
\end{array}\right\}-z\left\{\begin{array}{c}
w_{b, x x} \\
w_{b, y y} \\
2 w_{b, x y}
\end{array}\right\}-f(z)\left\{\begin{array}{c}
w_{s, x x} \\
w_{s, y y} \\
2 w_{s, x y}
\end{array}\right\}, \\
& \left\{\begin{array}{c}
\gamma_{x z} \\
\gamma_{y z}
\end{array}\right\}=g(z)\left\{\begin{array}{c}
w_{s, x} \\
w_{s, y}
\end{array}\right\},
\end{aligned}
$$

where

$$
\begin{aligned}
g(z) & =1-f(z), \\
z & =5\left[\frac{1}{4}-\left(\frac{z}{h}\right)^{2}\right] .
\end{aligned}
$$

If we denote membrane strains $\boldsymbol{\varepsilon}_{m}$, bending curvatures $\boldsymbol{\kappa}_{b}$, shear curvatures $\boldsymbol{\kappa}_{s}$, and shear strains $\boldsymbol{\varepsilon}_{s}$ as

$$
\begin{aligned}
& \boldsymbol{\varepsilon}_{m}=\left\{\begin{array}{lll}
u_{0, x} & v_{0, y} & \left(u_{0, y}+v_{0, x}\right)
\end{array}\right\}^{T}, \\
& \boldsymbol{\kappa}_{b}=-\left\{\begin{array}{lll}
w_{b, x x} & w_{b, y y} & 2 w_{b, x y}
\end{array}\right\}^{T}, \\
& \boldsymbol{\kappa}_{s}=-\left\{\begin{array}{lll}
w_{s, x x} & w_{s, y y} & 2 w_{s, x y}
\end{array}\right\}^{T}, \\
& \boldsymbol{\varepsilon}_{s}=\left\{\begin{array}{lll}
w_{s, x} & w_{s, y}
\end{array}\right\}^{T},
\end{aligned}
$$

then the strains in equation (7) can be written in the form

$$
\begin{aligned}
& \varepsilon_{1}=\varepsilon_{m}+z \boldsymbol{\kappa}_{b}+f(z) \kappa_{s}, \\
& \varepsilon_{2}=g(z) \varepsilon_{s},
\end{aligned}
$$

with $\varepsilon_{1}=\left\{\begin{array}{lll}\varepsilon_{x} & \varepsilon_{y} & \gamma_{x y}\end{array}\right\}^{T}$ and $\varepsilon_{2}=\left\{\begin{array}{ll}\gamma_{x z} & \gamma_{y x}\end{array}\right\}^{T}$.

The constitutive equations for the plate based on linear behaviour assumption are of the forms

$$
\boldsymbol{\sigma}_{1}=\mathrm{C}_{1}^{(k)} \varepsilon_{1}, \quad \boldsymbol{\sigma}_{2}=\mathrm{C}_{2}^{(k)} \varepsilon_{2},
$$

where $\boldsymbol{\sigma}_{1}=\left\{\begin{array}{lll}\sigma_{x} & \sigma_{y} & \tau_{x y}\end{array}\right\}^{T}, \boldsymbol{\sigma}_{2}=\left\{\begin{array}{ll}\tau_{x z} & \tau_{y z}\end{array}\right\}^{T}$, and

$$
\begin{aligned}
& \mathbf{C}_{1}^{(k)}=\left[\begin{array}{ccc}
Q_{11}^{(k)} & Q_{12}^{(k)} & 0 \\
Q_{12}^{(k)} & Q_{22}^{(k)} & 0 \\
0 & 0 & Q_{66}^{(k)}
\end{array}\right], \\
& \mathbf{C}_{2}^{(k)}=\left[\begin{array}{cc}
Q_{55}^{(k)} & 0 \\
0 & Q_{44}^{(k)}
\end{array}\right],
\end{aligned}
$$

with

$$
\begin{aligned}
& Q_{11}^{(k)}=Q_{22}^{(k)}=\frac{E_{f}^{(k)}}{1-v_{f}^{2(k)}}, \\
& Q_{12}^{(k)}=v_{f}^{(k)} Q_{11}^{(k)}, Q_{44}^{(k)}=Q_{55}^{(k)}=Q_{66}^{(k)}=\frac{E_{f}^{(k)}}{2\left(1+v_{f}^{(k)}\right)} .
\end{aligned}
$$

The shear stresses $\tau_{x z}$ and $\tau_{y z}$, as seen from equations (7), (8), and (11), vanish on the plate surface for the present RTSDT. By setting $f(z)=0$ and $g(z)=\psi$, with $\psi$ being a shear correction factor, the above equations result in equations of the RFSDT.
2.3. Energy Expressions. Instead of deriving differential equation of motion, the equation of motion in the context of finite element analysis will be derived. Assuming the plate is divided into a number of elements, Hamilton's principle for free vibration states that

$$
\delta \int_{t_{1}}^{t_{2}}\left[\sum^{\mathrm{nEP}}\left(U_{e}^{P}-\mathscr{T}_{e}\right)+\sum^{\mathrm{nEF}} U_{e}^{F}\right] \mathrm{d} t=0,
$$

where $\mathrm{nEP}$ and $\mathrm{nEF}$ are, respectively, the total number of elements used for plate and foundation; $U_{e}^{P}$ and $U_{e}^{F}$ are, respectively, the strain energies stemming from the plate and foundation deformation; and $\mathscr{T}_{e}$ is the element kinetic energy. Hamilton's principle leads to discrete equation of motion in the form

$$
\mathrm{MD}+\mathrm{KD}=\mathbf{0}
$$

where $\mathbf{M}, \mathbf{K}, \mathbf{D}$, and $\ddot{\mathbf{D}}$ are, respectively, the global mass matrix, stiffness matrix, and vectors of nodal displacements and accelerations. Assuming a harmonic form for the vector of nodal displacements, equation (15) leads to an eigenvalue problem for determining the frequency $\omega$ as

$$
\left(\mathbf{K}-\omega^{2} \mathbf{M}\right) \overline{\mathbf{D}}=\mathbf{0}
$$

where $\omega$ is the frequency and $\overline{\mathbf{D}}$ is the vibration amplitude.

The strain energy $U_{e}^{P}$ for an element is given by

$$
\begin{aligned}
U_{e}^{P} & =\frac{1}{2} \int_{V_{e}}\left(\boldsymbol{\sigma}_{1}^{T} \boldsymbol{\varepsilon}_{1}+\boldsymbol{\sigma}_{2}^{T} \boldsymbol{\varepsilon}_{2}\right) \mathrm{d} V \\
& =\frac{1}{2} \int_{\Omega_{e}} \int_{-h / 2}^{h / 2}\left(\boldsymbol{\varepsilon}_{1}^{T} \mathbf{C}_{1}^{(k)} \boldsymbol{\varepsilon}_{1}+\boldsymbol{\varepsilon}_{2}^{T} \mathbf{C}_{2}^{(k)} \boldsymbol{\varepsilon}_{2}\right) \mathrm{d} z \mathrm{~d} \Omega
\end{aligned}
$$

where $V_{e}$ and $\Omega_{e}$ are, respectively, the volume and midplane area of the element and $\mathrm{d} \Omega=\mathrm{d} x \mathrm{~d} y$ for the present rectangular element.

By expressing $\varepsilon_{1}$ in the form

$$
\boldsymbol{\varepsilon}_{1}=\left[\begin{array}{lll}
\mathbf{I}_{3} & z \mathbf{I}_{3} & f(z) \mathbf{I}_{3}
\end{array}\right]\left[\begin{array}{lll}
\boldsymbol{\varepsilon}_{m} & \boldsymbol{\kappa}_{b} & \boldsymbol{\kappa}_{s}
\end{array}\right]^{T}
$$

with $\mathbf{I}_{3}$ being a $(3 \times 3)$ order identity matrix, one can write the strain energy (17) in the form

$$
U_{e}^{P}=\frac{1}{2} \int_{\Omega_{e}}\left\{\left[\begin{array}{c}
\boldsymbol{\varepsilon}_{m} \\
\boldsymbol{\kappa}_{b} \\
\boldsymbol{\kappa}_{s}
\end{array}\right]^{T}\left[\begin{array}{lll}
\mathbf{A}_{0} & \mathbf{A}_{1} & \mathbf{A}_{3} \\
\mathbf{A}_{1} & \mathbf{A}_{2} & \mathbf{A}_{4} \\
\mathbf{A}_{3} & \mathbf{A}_{4} & \mathbf{A}_{5}
\end{array}\right]\left[\begin{array}{l}
\boldsymbol{\varepsilon}_{m} \\
\boldsymbol{\kappa}_{b} \\
\boldsymbol{\kappa}_{s}
\end{array}\right]+\boldsymbol{\varepsilon}_{2}^{T} \mathbf{D}_{s} \boldsymbol{\varepsilon}_{2}\right\} \mathrm{d} x \mathrm{~d} y,
$$

where

$$
\begin{aligned}
\left(\mathbf{A}_{0}, \mathbf{A}_{1}, \mathbf{A}_{2}, \mathbf{A}_{3}, \mathbf{A}_{4}, \mathbf{A}_{5}\right)= & \sum_{k=1}^{3} \int_{z_{k-1}}^{z_{k}} \\
& {\left[1, z, z^{2}, f(z), z f(z), f^{2}(z)\right] \mathbf{C}_{1}^{(k)} \mathrm{d} z, } \\
\mathbf{D}_{s}= & \sum_{k=1}^{3} \int_{z_{k-1}}^{z_{k}} g^{2}(z) \mathbf{C}_{2}^{(k)} \mathrm{d} z .
\end{aligned}
$$


The strain energy for the RFSDT is obtained by removing the terms corresponding to the shear curvature $\boldsymbol{\kappa}_{s}$ in equation (19) and setting $g(z)$ in equation (20) to $\psi$.

The strain energy stemming from the foundation deformation is simply given by

$$
\begin{aligned}
U_{e}^{F}= & \frac{1}{2} \int_{\Omega_{e}}\left[k_{W} w^{2}+k_{G}\left(w_{x}^{2}+w_{y}^{2}\right)\right] \mathrm{d} x \mathrm{~d} y \\
= & \frac{1}{2} \int_{\Omega_{e}}\left[k_{W}\left(w_{b}+w_{s}\right)^{2}+k_{G}\left(w_{b, x}+w_{s, x}\right)^{2}\right. \\
& \left.+k_{G}\left(w_{b, y}+w_{s, y}\right)^{2}\right] \mathrm{d} x \mathrm{~d} y .
\end{aligned}
$$

Using matrix $\mathbf{I}_{3}$, one can write the displacement field in equation (5) in the form

$$
\mathbf{u}=\left\{\begin{array}{lll}
u & v & w
\end{array}\right\}^{T}=\left[\begin{array}{lll}
\mathbf{I}_{3} & z \mathbf{I}_{3} & f(z) \mathbf{I}_{3}
\end{array}\right]\left[\begin{array}{lll}
\mathbf{u}_{m} & \mathbf{u}_{b} & \mathbf{u}_{s}
\end{array}\right]^{T},
$$

with

$$
\begin{aligned}
& \mathbf{u}_{m}=\left\{\begin{array}{lll}
u_{0} & v_{0} & w_{b}+w_{s}
\end{array}\right\}^{T}, \\
& \mathbf{u}_{b}=\left\{\begin{array}{lll}
-w_{b, x} & -w_{b, y} & 0
\end{array}\right\}^{T}, \\
& \mathbf{u}_{s}=\left\{\begin{array}{lll}
-w_{s, x} & -w_{s, y} & 0
\end{array}\right\}^{T} .
\end{aligned}
$$
form

The kinetic energy for the element can be written in the

$$
\mathscr{T}_{e}=\frac{1}{2} \int_{V} \rho \dot{u}^{T} \dot{u} \mathrm{~d} V=\frac{1}{2} \int_{\Omega_{e}}\left[\begin{array}{c}
\dot{u}_{m} \\
\dot{u}_{b} \\
\dot{u}_{s}
\end{array}\right]^{T}\left[\begin{array}{lll}
I_{0} & I_{1} & I_{3} \\
I_{1} & I_{2} & I_{4} \\
I_{3} & I_{4} & I_{5}
\end{array}\right]\left[\begin{array}{c}
\dot{u}_{m} \\
\dot{u}_{b} \\
\dot{u}_{s}
\end{array}\right] \mathrm{d} x \mathrm{~d} y,
$$

where overdot denotes the derivative with respect to the time variable $t$ and $I_{i}(i=0, \ldots, 5)$ are the mass moments, defined as

$$
\left(I_{0}, I_{1}, I_{2}, I_{3}, I_{4}, I_{5}\right)=\sum_{k=1}^{3} \int_{z_{k-1}}^{z_{k}} \rho_{f}^{(k)}\left[1, z, z^{2}, f(z), z f(z), f^{2}(z)\right] \mathrm{d} z,
$$

with the effective mass density $\rho_{f}^{(k)}$ given by equation (4).

\section{Element Formulations}

The stiffness and mass matrices for a four-node quadrilateral element based on the RTSDT and RFSDT are derived in this section. The nodal displacements and derivatives of the bending and shear displacements are taken as degrees of freedom, and the element vector of nodal displacements contains 40 components as

$$
\underset{40 \times 1}{\mathbf{d}}=\left\{\begin{array}{lll}
\mathbf{d}_{m} & \mathbf{d}_{b} & \mathbf{d}_{s}
\end{array}\right\}^{T},
$$

where $\mathbf{d}_{m}=\left\{\begin{array}{ll}\mathbf{d}_{u} & \mathbf{d}_{v}\end{array}\right\}^{T}$ with

$$
\begin{aligned}
\underset{4 \times 1}{\mathbf{d}_{u}} & =\left\{\begin{array}{llll}
u_{01} & u_{02} & u_{03} & u_{04}
\end{array}\right\}^{T}, \\
\underset{4 \times 1}{\mathbf{d}_{v}} & =\left\{\begin{array}{llll}
v_{01} & v_{02} & v_{03} & v_{04}
\end{array}\right\}^{T}, \\
\underset{16 \times 1}{\mathbf{d}_{b}} & =\left\{\begin{array}{lllll}
\Delta_{b 1} & \Delta_{b 2} & \Delta_{b 3} & \Delta_{b 4}
\end{array}\right\}^{T}, \\
\underset{16 \times 1}{\mathbf{d}_{s}} & =\left\{\begin{array}{lllll}
\Delta_{s 1} & \Delta_{s 2} & \Delta_{s 3} & \Delta_{s 4}
\end{array}\right\}^{T},
\end{aligned}
$$

with

$$
\begin{aligned}
& \Delta_{b i}=\left\{\begin{array}{llll}
w_{b i} & w_{b, x i} & w_{b, y i} & w_{b, x y i}
\end{array}\right\}^{T}, \\
& \Delta_{s i}=\left\{\begin{array}{lllll}
w_{b i} & w_{s, x i} & w_{s, y i} & w_{s, x y i}
\end{array}\right\}^{T}, \quad(i=1, \ldots, 4) .
\end{aligned}
$$

Lagrange and Hermite polynomials are employed herein to interpolate the displacements as [39]

$$
\begin{aligned}
& u_{0}=\sum_{i=1}^{4} N_{i} d_{u i}, \\
& v_{0}=\sum_{i=1}^{4} N_{i} d_{v i}, \\
& w_{b}=\sum_{i=1}^{16} H_{i} d_{b i}, \\
& w_{s}=\sum_{i=1}^{16} H_{i} d_{s i},
\end{aligned}
$$

where $N_{i}(i=1, \ldots, 4)$ and $H_{i}(i=1, \ldots, 16)$ are, respectively, the Lagrange and Hermite functions. In a matrix form, equation (30) can be written as

$$
\begin{aligned}
\left\{\begin{array}{ll}
u_{0} & v_{0}
\end{array}\right\}^{T} & =\left[\begin{array}{cc}
\mathbf{N} & \mathbf{0} \\
\mathbf{0} & \mathbf{N}
\end{array}\right] \mathbf{d}_{m}, \\
w_{b} & =\mathbf{H d}_{b} \\
w_{s} & =\mathbf{H d}_{s}
\end{aligned}
$$

where $\mathbf{N}=\left[\begin{array}{llll}N_{1} & N_{2} & N_{3} & N_{4}\end{array}\right]$ and $\mathbf{H}=\left[\begin{array}{llll}H_{1} & H_{2} & \ldots & H_{16}\end{array}\right]$ are the matrices of the interpolation functions.

Using the above interpolations, one can write the strains and curvatures in the forms

$$
\boldsymbol{\varepsilon}_{m}=\mathbf{B}_{m} \mathbf{d}_{m}, \quad \boldsymbol{\kappa}_{b}=\mathbf{C}_{b} \mathbf{d}_{b}, \quad \boldsymbol{\kappa}_{s}=\mathbf{C}_{s} \mathbf{d}_{s}, \quad \boldsymbol{\varepsilon}_{s}=\mathbf{B}_{s} \mathbf{d}_{s},
$$

where the strain-displacement matrices are of the forms

$$
\begin{aligned}
& \mathbf{B}_{3 \times 8}=\left[\begin{array}{cc}
\mathbf{N}_{, x} & \mathbf{0} \\
\mathbf{0} & \mathbf{N}_{, y} \\
\mathbf{N}_{, y} & \mathbf{N}_{, x}
\end{array}\right], \\
& \underset{3 \times 16}{\mathbf{C}_{b}=} \underset{3 \times 16}{\mathbf{C}_{3}}=-\left[\begin{array}{c}
\mathbf{H}_{, x x} \\
\mathbf{H}_{, y y} \\
2 \mathbf{H}_{, x y}
\end{array}\right], \\
& \underset{2 \times 16}{\mathbf{B}_{s}}=\left[\begin{array}{c}
\mathbf{H}_{, x} \\
\mathbf{H}_{, y}
\end{array}\right] .
\end{aligned}
$$

Substituting equations (32) and (33) into equation (19), one can write the strain energy $U_{e}^{P}$ in the form 


$$
U_{e}^{P}=\frac{1}{2} \mathbf{d}^{T} \mathbf{k}_{e}^{P} \mathbf{d}=\frac{1}{2}\left\{\begin{array}{c}
\mathbf{d}_{m} \\
\mathbf{d}_{b} \\
\mathbf{d}_{s}
\end{array}\right\}^{T}\left[\begin{array}{ccc}
\mathbf{k}_{m m} & \mathbf{k}_{m b} & \mathbf{k}_{m s} \\
\mathbf{k}_{m b}^{T} & \mathbf{k}_{b b} & \mathbf{k}_{b s} \\
\mathbf{k}_{m s}^{T} & \mathbf{k}_{b s}^{T} & \mathbf{k}_{s s}
\end{array}\right]\left\{\begin{array}{c}
\mathbf{d}_{m} \\
\mathbf{d}_{b} \\
\mathbf{d}_{s}
\end{array}\right\}
$$

where $\mathbf{k}_{e}^{P}$ is the element stiffness matrix resulted from the plate deformation; $\mathbf{k}_{m m}, \mathbf{k}_{b b}$, and $\mathbf{k}_{s s}$ are, respectively, the membrane, bending, and shear stiffness matrices with the following forms

$$
\begin{aligned}
\underset{8 \times 8}{\mathbf{k}_{m m}} & =\int_{\Omega_{e}} \mathbf{B}_{m}^{T} \mathbf{A}_{0} \mathbf{B}_{m} \mathrm{~d} x \mathrm{~d} y, \\
\underset{16 \times 16}{\mathbf{k}_{b b}} & =\int_{\Omega_{e}} \mathbf{C}_{b}^{T} \mathbf{A}_{2} \mathbf{C}_{b} \mathrm{~d} x \mathrm{~d} y, \\
\underset{16 \times 16}{\mathbf{k}_{s s}} & =\int_{\Omega_{e}} \mathbf{C}_{s}^{T} \mathbf{A}_{5} \mathbf{C}_{s} \mathrm{~d} x \mathrm{~d} y+\int_{\Omega_{e}} \mathbf{B}_{s}^{T} \mathbf{D}_{s} \mathbf{B}_{s} \mathrm{~d} x \mathrm{~d} y,
\end{aligned}
$$

and the coupling stiffness matrices $\mathbf{k}_{m b}, \mathbf{k}_{m s}$, and $\mathbf{k}_{b s}$ have the forms

$$
\begin{aligned}
& \underset{8 \times 16}{\mathbf{k}_{m b}}=\int_{\Omega_{e}} \mathbf{B}_{m}^{T} \mathbf{A}_{1} \mathbf{C}_{b} \mathrm{~d} x \mathrm{~d} y, \\
& \underset{8 \times 16}{\mathbf{k}_{m s}}=\int_{\Omega_{e}} \mathbf{B}_{m}^{T} \mathbf{A}_{3} \mathbf{C}_{s} \mathrm{~d} x \mathrm{~d} y, \\
& \underset{16 \times 16}{\mathbf{k}_{b s}}=\int_{\Omega_{e}} \mathbf{C}_{b}^{T} \mathbf{A}_{4} \mathbf{C}_{s} \mathrm{~d} x \mathrm{~d} y .
\end{aligned}
$$

The stiffness matrix for the element based on the RFSDT is simply obtained by setting the terms corresponding to $\mathbf{C}_{s}$ in equations (35) and (36) to zeros.

The strain energy $U_{e}^{F}$ given by equation (21) can now be written in the form

$$
U_{e}^{F}=\frac{1}{2} \mathbf{d}^{T} \mathbf{k}_{e}^{F} \mathbf{d},
$$

where the element foundation stiffness $\mathbf{k}_{e}^{F}$ has the form

$$
\underset{40 \times 40}{\mathbf{k}_{e}^{F}}=\left[\begin{array}{ccc}
\mathbf{0} & \mathbf{0} & \mathbf{0} \\
\mathbf{0} & \mathbf{k}_{b b}^{F} & \mathbf{k}_{b s}^{F} \\
\mathbf{0} & \mathbf{k}_{b s}^{F} & \mathbf{k}_{s s}^{F}
\end{array}\right],
$$

with

$$
\underset{16 \times 16}{\mathbf{k}_{b b}^{F}}=\mathbf{k}_{s s}^{F}=\mathbf{k}_{b s}^{F}=\int_{\Omega_{e}}\left(\mathbf{H}^{T} k_{W} \mathbf{H}+\mathbf{H}_{, x}^{T} k_{G} \mathbf{H}_{, x}+\mathbf{H}_{, y}^{T} k_{G} \mathbf{H}_{, y}\right) \mathrm{d} x \mathrm{~d} y .
$$

The kinetic energy $\mathscr{T}_{e}$ in equation (24) can also be written in the form

$$
\mathscr{T}_{e}=\frac{1}{2} \dot{d}^{T} \mathbf{m}_{e} \dot{d}=\frac{1}{2}\left\{\begin{array}{c}
\dot{d}_{m} \\
\dot{d}_{b} \\
\dot{d}_{s}
\end{array}\right\}^{T}\left[\begin{array}{ccc}
\mathbf{m}_{m m} & \mathbf{m}_{m b} & \mathbf{m}_{m s} \\
\mathbf{m}_{m b}^{T} & \mathbf{m}_{b b} & \mathbf{m}_{b s} \\
\mathbf{m}_{m s}^{T} & \mathbf{m}_{b s}^{T} & \mathbf{m}_{s s}
\end{array}\right]\left\{\begin{array}{c}
\dot{d}_{m} \\
\dot{d}_{b} \\
\dot{d}_{s}
\end{array}\right\},
$$

where $\mathbf{m}_{e}$ is the element mass matrix formed from the following submatrices:

$$
\begin{aligned}
\underset{8 \times 8}{\mathbf{m}_{m m}} & =\int_{\Omega_{e}}\left[\begin{array}{cc}
\mathbf{N}^{T} I_{0} \mathbf{N} & \mathbf{0}, \\
\mathbf{0} & \mathbf{N}^{T} I_{0} \mathbf{N}
\end{array}\right] \mathrm{d} x \mathrm{~d} y, \\
\underset{16 \times 16}{\mathbf{m}_{b b}} & =\int_{\Omega_{e}}\left(\mathbf{H}^{T} I_{0} \mathbf{H}+\mathbf{H}_{, x}^{T} I_{2} \mathbf{H}_{, x}+\mathbf{H}_{, y}^{T} I_{2} \mathbf{H}_{, y}\right) \mathrm{d} x \mathrm{~d} y, \\
\underset{16 \times 16}{\mathbf{m}_{s s}} & =\int_{\Omega_{e}}\left(\mathbf{H}^{T} I_{0} \mathbf{H}+\mathbf{H}_{, x}^{T} I_{5} \mathbf{H}_{, x}+\mathbf{H}_{, y}^{T} I_{5} \mathbf{H}_{, y}\right) \mathrm{d} x \mathrm{~d} y,
\end{aligned}
$$

and the coupling mass matrices have the forms

$$
\begin{aligned}
& \underset{8 \times 16}{\mathbf{m}_{m b}}=-\int_{\Omega_{e}}\left[\begin{array}{l}
\mathbf{N}^{T} I_{1} \mathbf{H}_{, x} \\
\mathbf{N}^{T} I_{1} \mathbf{H}_{, y}
\end{array}\right] \mathrm{d} x \mathrm{~d} y, \\
& \underset{8 \times 16}{\mathbf{m}_{m s}}=-\int_{\Omega_{e}}\left[\begin{array}{l}
\mathbf{N}^{T} I_{3} \mathbf{H}_{, x} \\
\mathbf{N}^{T} I_{3} \mathbf{H}_{, y}
\end{array}\right] \mathrm{d} x \mathrm{~d} y, \\
& \mathbf{m}_{16 \times 16}=\int_{\Omega_{e}}\left(\mathbf{H}^{T} I_{0} \mathbf{H}+\mathbf{H}_{, x}^{T} I_{4} \mathbf{H}_{, x}+\mathbf{H}_{, y}^{T} I_{4} \mathbf{H}_{, y}\right) \mathrm{d} x \mathrm{~d} y .
\end{aligned}
$$

Since $f(z)=0$ in the RFSDT, then $I_{3}=I_{4}=I_{5}=0$, and thus the element mass matrix for the RFSDT element is obtained by setting the terms corresponding to $I_{3}, I_{4}$, and $I_{5}$ in equations (41) and (42) to zeros.

\section{Numerical Results}

Numerical investigation is carried out in this section to study the effect of various parameters on the vibration of the FGSW plate. Otherwise stated, an FGSW plate with $a / b=2$ formed from aluminum $(\mathrm{Al})$ and alumina $\left(\mathrm{Al}_{2} \mathrm{O}_{3}\right)$ with the following properties is employed:

(i) $E_{m}=70 \mathrm{GPa}, v_{m}=0.3$, and $\rho_{m}=2707 \mathrm{~kg} / \mathrm{m}^{3}$ for $\mathrm{Al}$

(ii) $E_{c}=380 \mathrm{GPa}, v_{c}=0.3$, and $\rho_{c}=3800 \mathrm{~kg} / \mathrm{m}^{3}$ for $\mathrm{Al}_{2} \mathrm{O}_{3}$

Three types of boundary conditions, namely, simply supported at all edges (SSSS), simply supported at two longer edges and clamped at the others (SCSC), and clamped at all edges (CCCC), are considered. For convenience of discussion, the following dimensionless parameters for the plate frequencies and foundation stiffness introduced in [40] are adopted herewith

$$
\begin{aligned}
& \mu_{i}=\frac{\omega_{i} a^{2}}{h} \sqrt{\frac{\rho_{0}}{E_{0}}}, \\
& k_{1}=\frac{k_{W} a^{4}}{D_{c}}, \\
& k_{2}=\frac{k_{G} a^{2}}{D_{c}},
\end{aligned}
$$

where $\omega_{i}$ is the $i$ th frequency, $D_{c}=E_{c} h^{3} / 12\left(1-v^{2}\right), E_{0}=1$ $\mathrm{GPa}$, and $\rho_{0}=1 \mathrm{~kg} / \mathrm{m}^{3}$. Also, two dimensionless parameters, $r_{a}=a_{f} / a$ and $r_{b}=b_{f} / b$, are used for the foundation supporting area. Three numbers in brackets are used to denote the layer thickness ratio, e.g., (1-2-1) means that the thickness ratio of the bottom, core, and top layers is $1: 2: 1$. A shear correction factor $\psi=5 / 6$ is used for the RFSDT. 
TABLE 1: Comparison of frequency parameter $\mu_{1}$ for SSSS square plate fully supported by Pasternak foundation.

\begin{tabular}{|c|c|c|c|c|c|c|c|c|}
\hline$a / h$ & $n$ & $\left(k_{1}, k_{2}\right)$ & Source & $(1-0-1)$ & $(2-1-2)$ & $(1-1-1)$ & $(2-2-1)$ & $(1-2-1)$ \\
\hline \multirow{12}{*}{5} & \multirow{6}{*}{2} & \multirow{3}{*}{$(10,10)$} & Ref. [40] & 1.32314 & 1.33409 & 1.34691 & 1.36107 & 1.37133 \\
\hline & & & RFSDT & 1.32372 & 1.33214 & 1.34386 & 1.36008 & 1.36842 \\
\hline & & & RTSDT & 1.32852 & 1.33743 & 1.34880 & 1.36440 & 1.37253 \\
\hline & & \multirow{3}{*}{$(100,100)$} & Ref. [40] & 2.56208 & 2.68234 & 2.75786 & 2.79373 & 2.84764 \\
\hline & & & RFSDT & 2.50594 & 2.64167 & 2.72792 & 2.76587 & 2.82687 \\
\hline & & & RTSDT & 2.50743 & 2.64291 & 2.72897 & 2.76662 & 2.82769 \\
\hline & \multirow{6}{*}{10} & \multirow{4}{*}{$(10,10)$} & Ref. [40] & 1.30224 & 1.30448 & 1.31193 & 1.32742 & 1.33389 \\
\hline & & & RFSDT & 1.31403 & 1.31334 & 1.31937 & 1.33658 & 1.34044 \\
\hline & & & RTSDT & 1.31750 & 1.31919 & 1.32520 & 1.34157 & 1.34550 \\
\hline & & & Ref. [40] & 2.31764 & 2.50435 & 2.61784 & 2.67072 & 2.74945 \\
\hline & & \multirow[t]{2}{*}{$(100,100)$} & RFSDT & 2.30053 & 2.49358 & 2.61182 & 2.66423 & 2.74622 \\
\hline & & & RTSDT & 2.30245 & 2.49521 & 2.61322 & 2.66492 & 2.74731 \\
\hline \multirow{12}{*}{100} & \multirow{6}{*}{2} & \multirow{4}{*}{$(10,10)$} & Ref. [40] & 1.42000 & 1.43000 & 1.44444 & 1.46227 & 1.47402 \\
\hline & & & RFSDT & 1.40810 & 1.41550 & 1.42804 & 1.44905 & 1.45836 \\
\hline & & & RTSDT & 1.40895 & 1.41618 & 1.42861 & 1.44957 & 1.45880 \\
\hline & & & Ref. [40] & 3.34906 & 3.33441 & 3.32829 & 3.32997 & 3.32610 \\
\hline & & \multirow[t]{2}{*}{$(100,100)$} & RFSDT & 3.34422 & 3.32841 & 3.32566 & 3.32437 & 3.31938 \\
\hline & & & RTSDT & 3.34622 & 3.32998 & 3.32695 & 3.32553 & 3.32034 \\
\hline & \multirow{6}{*}{10} & \multirow{3}{*}{$(10,10)$} & Ref. [40] & 1.40234 & 1.3967 & 1.40285 & 1.42192 & 1.42781 \\
\hline & & & RFSDT & 1.40072 & 1.39395 & 1.39830 & 1.42029 & 1.42330 \\
\hline & & & RTSDT & 1.40189 & 1.39488 & 1.39907 & 1.42099 & 1.42388 \\
\hline & & \multirow{3}{*}{$(100,100)$} & Ref. [40] & 3.37718 & 3.34801 & 3.33315 & 3.33266 & 3.3225 \\
\hline & & & RFSDT & 3.37670 & 3.34706 & 3.33583 & 3.33216 & 3.32075 \\
\hline & & & RTSDT & 3.37952 & 3.34925 & 3.33763 & 3.33377 & 3.32208 \\
\hline
\end{tabular}

The accuracy of the formulated elements is firstly verified. To this end, Table 1 compares the fundamental frequency parameters of a SSSS square plate fully resting on the Pasternak foundation obtained by the elements in the present work to the result of Akavci [40]. Regardless of the material index, layer thickness ratio, and foundation stiffness, Table 1 shows a good agreement between the frequency parameters of the present work with that of Ref. [40], where the hyperbolic shear deformation theory and Navier technique have been used. Note that the result in Table 1 was obtained for the plate made of aluminum and zirconia with the material data given in [40].

Tables 2-4, respectively, list the fundamental frequency parameter of the SSSS, SCSC, and CCCC plates with $a / h=5$, $\left(r_{a}, r_{b}\right)=(1 / 4,1 / 4)$, and various values of the index $n$ and the layer thickness ratio. The frequency parameter in the tables decreases by the increase of the index $n$, and it increases by increasing the core thickness, regardless of the boundary condition and the foundation stiffness. The dependence of the frequency parameter upon the grading index and the layer thickness ratio can be explained by the change of the constituent volume fraction, as seen from equation (1), and this leads to the change of the plate rigidities $A_{i j}$. Though the mass moments $I_{i j}$ also alter by the change of the index $n$, the change of $A_{i j}$ is more significant than that of $I_{i j}$, and thus the decrease of the frequency by increasing $n$ is resulted from the more significant decrease of $A_{i j}$. As expected, at the given values of the index $n$ and the layer thickness ratio, the frequency prameter of the SSSS plate is smallest while that of the CCCC plate is highest. The tables also show that the RTSDT element-based frequency parameters are slightly higher than that based on the RFSDT
TABLE 2: Frequency parameter $\mu_{1}$ of SSSS plate for $a / h=5$ and $\left(r_{a}, r_{b}\right)=(1 / 4,1 / 4)$.

\begin{tabular}{|c|c|c|c|c|c|c|c|}
\hline$\left(k_{1}, k_{2}\right)$ & $n$ & Element & $(1-0-1)$ & $(2-1-2)$ & $(1-1-1)$ & $(2-2-1)$ & (1-2- \\
\hline \multirow{8}{*}{$(10,10)$} & \multirow{2}{*}{0.3} & RFSDT & 2.0482 & 2.1228 & 2.1887 & 2.2474 & 2.2948 \\
\hline & & RTSDT & 2.0620 & 2.1366 & 2.2012 & 2.2583 & 2.3046 \\
\hline & \multirow{2}{*}{0.5} & RFSDT & 1.8705 & 1.9564 & 2.0366 & 2.1124 & 2.1698 \\
\hline & & RTSDT & 1.8854 & 1.9715 & 2.0503 & 2.1242 & 2.1806 \\
\hline & \multirow{2}{*}{1} & RFSDT & 1.6586 & 1.7484 & 1.8420 & 1.9412 & 2.0085 \\
\hline & & RTSDT & 1.6746 & 1.7643 & 1.8564 & 1.9538 & 2.0201 \\
\hline & \multirow[b]{2}{*}{5} & RFSDT & 1.4565 & 1.5062 & 1.5891 & 1.7195 & 1.7828 \\
\hline & & RTSDT & 1.4738 & & 1.6050 & 1.7334 & 1.7956 \\
\hline \multirow{8}{*}{$(50,50)$} & \multirow{2}{*}{0.3} & RFSDT & 249 & 55 & 52 & 30 & 703 \\
\hline & & RTs & 2.1409 & 53 & 2.2794 & 353 & 2.3813 \\
\hline & \multirow{2}{*}{0.5} & RFSDT & 1.9478 & 2.0345 & 2.1147 & 2.1892 & 2.2468 \\
\hline & & RTSDT & 1.9656 & 2.0520 & 2.1305 & 2.2029 & 2.2592 \\
\hline & \multirow[b]{2}{*}{1} & RFSDT & 1.7348 & 1.8271 & 1.9215 & 2.0192 & 2.0875 \\
\hline & & RTSDT & 1.7549 & 1.8465 & 1.9388 & 2.0342 & 2.1010 \\
\hline & \multirow{2}{*}{5} & RFSDT & 1.5247 & 1.5823 & 1.6684 & 1.7972 & 1.8637 \\
\hline & & RTSDT & 1.5477 & 1.6065 & 1.6889 & 1.8146 & 1.8795 \\
\hline \multirow{8}{*}{$(100,100)$} & \multirow{2}{*}{0.3} & RFSDT & 2.1689 & 2.2453 & 2.3122 & 2.3704 & 2.4185 \\
\hline & & RTSDT & 2.1878 & 2.2639 & 2.3289 & 2.3848 & 2.4316 \\
\hline & \multirow{2}{*}{0.5} & RFSDT & 1.9886 & 2.0779 & 2.1599 & 2.2350 & 2.2941 \\
\hline & & RTSDT & 2.0097 & 2.0987 & 2.1786 & 2.2512 & 2.3087 \\
\hline & & RFSDT & 1.7702 & 1.8666 & 1.9637 & 2.0623 & 2.1329 \\
\hline & & RTSDT & 1.7941 & 1.8898 & 1.9843 & 2.0802 & 2.1490 \\
\hline & & & 1.5504 & 1.6146 & 1.7047 & 1.8352 & 1.9056 \\
\hline & & RTSDT & 1.5776 & 1.6436 & 1.7295 & 1.8561 & 1.924 \\
\hline
\end{tabular}

element, irrespective of the boundary condition, the foundation stiffness, the material grading index, and the layer thickness ratio. The effect of the foundation supporting area on the vibration of the plate can be seen from Figures 2-4, 
TABLE 3: Frequency parameter $\mu_{1}$ of SCSC plate for $a / h=5$ and $\left(r_{a}, r_{b}\right)=(1 / 4,1 / 4)$.

\begin{tabular}{|c|c|c|c|c|c|c|c|}
\hline$\left(k_{1}, k_{2}\right)$ & $n$ & Element & $\begin{array}{c}(1-0- \\
1)\end{array}$ & $\begin{array}{c}(2-1- \\
2)\end{array}$ & $\begin{array}{c}(1-1- \\
1)\end{array}$ & $\begin{array}{c}(2-2- \\
1)\end{array}$ & $\begin{array}{c}(1-2- \\
1)\end{array}$ \\
\hline \multirow{8}{*}{$(10,10)$} & \multirow{2}{*}{0.3} & RFSDT & 2.3883 & 2.4775 & 2.5549 & 2.6183 & 2.6778 \\
\hline & & RTSDT & 2.4113 & 2.5007 & 2.5760 & 2.6366 & 2.6945 \\
\hline & \multirow{2}{*}{0.5} & RFSDT & 2.1815 & 2.2854 & 2.3802 & 2.4607 & 2.5350 \\
\hline & & RTSDT & 2.2063 & 2.3104 & 2.4030 & 2.4806 & 2.5533 \\
\hline & \multirow{2}{*}{1} & RFSDT & 1.9327 & 2.0435 & 2.1550 & 2.2582 & 2.3499 \\
\hline & & RTSDT & 1.9589 & 2.0698 & 2.1790 & 2.2792 & 2.3694 \\
\hline & \multirow{2}{*}{5} & RFSDT & 1.6855 & 1.7573 & 1.8591 & 1.9898 & 2.0885 \\
\hline & & RTSDT & 1.7132 & 1.7874 & 1.8853 & 2.0126 & 2.1099 \\
\hline \multirow{8}{*}{$(50,50)$} & \multirow{2}{*}{0.3} & RFSDT & 2.4407 & 2.5295 & 2.6065 & 2.6693 & 2.7283 \\
\hline & & RTSDT & 2.4648 & 2.5536 & 2.6283 & 2.6882 & 2.7455 \\
\hline & \multirow{2}{*}{0.5} & RFSDT & 2.2353 & 2.3390 & 2.4333 & 2.5130 & 2.5869 \\
\hline & & RTSDT & 2.2616 & 2.3653 & 2.4572 & 2.5338 & 2.6059 \\
\hline & \multirow[b]{2}{*}{1} & RFSDT & 1.9872 & 2.0988 & 2.2101 & 2.3123 & 2.4037 \\
\hline & & RTSDT & 2.0160 & 2.1271 & 2.2356 & 2.3345 & 2.4241 \\
\hline & \multirow{2}{*}{5} & RFSDT & 1.7367 & 1.8131 & 1.9161 & 2.0456 & 2.1449 \\
\hline & & RTSDT & 1.7685 & 1.8470 & 1.9451 & 2.0707 & 2.1679 \\
\hline \multirow{8}{*}{$\begin{array}{l}(100, \\
100)\end{array}$} & \multirow{2}{*}{0.3} & RFSDT & 2.4760 & 2.5644 & 2.6419 & 2.7049 & 2.7643 \\
\hline & & RTSDT & 2.5009 & 2.5905 & 2.6656 & 2.7254 & 2.7830 \\
\hline & \multirow{2}{*}{0.5} & RFSDT & 2.2675 & 2.3728 & 2.4681 & 2.5481 & 2.6226 \\
\hline & & RTSDT & 2.2964 & 2.4016 & 2.4941 & 2.5707 & 2.6432 \\
\hline & \multirow{2}{*}{1} & RFSDT & 2.0162 & 2.1305 & 2.2435 & 2.3463 & 2.4387 \\
\hline & & RTSDT & 2.0482 & 2.1619 & 2.2717 & 2.3707 & 2.4611 \\
\hline & \multirow[b]{2}{*}{5} & RFSDT & 1.7586 & 1.8404 & 1.9463 & 2.0774 & 2.1784 \\
\hline & & RTSDT & 1.7942 & 1.8786 & 1.9791 & 2.1052 & 2.2041 \\
\hline
\end{tabular}

TABLE 4: Frequency parameter $\mu_{1}$ of CCCC plate for $a / h=5$ and $\left(r_{a}, r_{b}\right)=(1 / 4,1 / 4)$.

\begin{tabular}{|c|c|c|c|c|c|c|c|}
\hline$\left(k_{1}, k_{2}\right)$ & $n$ & Element & $(1-0-1)$ & $(2-1-2)$ & $(1-1-1)$ & $(2-2-1)$ & $(1-2-1)$ \\
\hline \multirow{8}{*}{$(10,10)$} & \multirow{2}{*}{0.3} & RFSDT & 3.1143 & 3.2346 & 3.3343 & 3.4082 & 3.4861 \\
\hline & & RTSDT & 3.1748 & 3.2955 & 3.3908 & 3.4587 & 3.5333 \\
\hline & \multirow{2}{*}{0.5} & RFSDT & 2.8564 & 2.9999 & 3.1235 & 3.2173 & 3.3168 \\
\hline & & RTSDT & 2.9196 & 3.0641 & 3.1829 & 3.2702 & 3.3664 \\
\hline & \multirow{2}{*}{1} & RFSDT & 2.5384 & 2.6994 & 2.8480 & 2.9679 & 3.0948 \\
\hline & & RTSDT & 2.6044 & 2.7661 & 2.9093 & 3.0223 & 3.1461 \\
\hline & \multirow{2}{*}{5} & RFSDT & 2.1883 & 2.3297 & 2.4757 & 2.6264 & 2.7749 \\
\hline & & RTSDT & 2.2562 & 2.4049 & 2.5422 & 2.6843 & 2.8302 \\
\hline \multirow{8}{*}{$(50,50)$} & \multirow{2}{*}{0.3} & RFSDT & 3.1505 & 3.2704 & 3.3698 & 3.4434 & 3.5310 \\
\hline & & RTSDT & 3.2108 & 3.3311 & 3.4261 & 3.4937 & 3.5680 \\
\hline & \multirow{2}{*}{0.5} & RFSDT & 2.8932 & 3.0364 & 3.1596 & 3.2531 & 3.3522 \\
\hline & & RTSDT & 2.9567 & 3.1006 & 3.2190 & 3.3059 & 3.4017 \\
\hline & \multirow{2}{*}{1} & RFSDT & 2.5756 & 2.7366 & 2.8850 & 3.0045 & 3.1310 \\
\hline & & RTSDT & 2.6424 & 2.8037 & 2.9465 & 3.0590 & 3.1823 \\
\hline & \multirow{2}{*}{5} & RFSDT & 2.2242 & 2.3673 & 2.5136 & 2.6641 & 2.8125 \\
\hline & & RTSDT & 2.2940 & 2.4440 & 2.5812 & 2.7227 & 2.8681 \\
\hline \multirow{8}{*}{$(100,100)$} & \multirow{2}{*}{0.3} & RFSDT & 3.1743 & 3.2948 & 3.3946 & 3.4684 & 3.5463 \\
\hline & & RTSDT & 3.2358 & 3.3566 & 3.4518 & 3.5195 & 3.5940 \\
\hline & \multirow{2}{*}{0.5} & RFSDT & 2.9158 & 3.0599 & 3.1838 & 3.2777 & 3.3771 \\
\hline & & RTSDT & 2.9808 & 3.1255 & 3.2444 & 3.3314 & 3.4275 \\
\hline & \multirow{2}{*}{1} & RFSDT & 2.5961 & 2.7588 & 2.9082 & 3.0283 & 3.1554 \\
\hline & & RTSDT & 2.6649 & 2.8277 & 2.9712 & 3.0839 & 3.2077 \\
\hline & \multirow{2}{*}{5} & RFSDT & 2.2401 & 2.3865 & 2.5347 & 2.6862 & 2.8357 \\
\hline & & RTSDT & 2.3124 & 2.4660 & 2.6045 & 2.7465 & 2.8928 \\
\hline
\end{tabular}

where the first four vibration modes of the SSSS, SCSC, and CCCC plates with $n=0.5$ and $a / h=10$ are, respectively, illustrated for $\left(r_{a}, r_{b}\right)=(1 / 2,1 / 2)$ and $k_{1}=k_{2}=50$. The vibration modes of the plates partially supported by the foundation, as seen from the figures, are much different from that of the plates without or fully resting on the foundation, and the first and fouth modes of the plates partially supported by the foundation are no longer symmetrical. Note that Figures 2-4 (and all the figures below) are obtained by using the element based on the RTSDT.

To examine the influence of the foundation supporting area on the vibration frequency of the FGSW plate in some more detail, Table 5 lists the fundamental frequency parameters of the (2-1-2) SSSS plates for various values of the aspect ratio, foundation supporting area, and foundation stiffness. The frequency parameter in the table, as expected, increases with the increase of the foundation supporting area and the foundation stiffness, regardless of the material index and the aspect ratio. The difference between the frequency parameter obtained by the two elements can be seen again from the table, and the frequencies obtained by the RTSDT element are always higher than the ones obtained by the RFSDT element, regardless of the aspect ratio, the foundation stiffness, and the foundation supporting area. A careful examination of Table 5 shows that the foundation supporting area plays an important role on the dependence of the frequency parameter upon the material index $n$, and the decrease of the parameter $\mu_{1}$ with the increase of $n$ is less significant for the plate supported by a larger foundation area, regardless of the aspect ratio. For example, with $a / h=10$ and $\left(k_{1}, k_{2}\right)=(10,10)$, a decrease of $30.83 \%$ of the frequency parameter $\mu_{1}$ based on the RTSDT element when increasing the index $n$ from 0.3 to 10 is seen from Table 5 for $\left(r_{a}, r_{b}\right)=(1 / 4,1 / 4)$, while the corresponding values are $24.95 \%$ and $19.02 \%$ in case $\left(r_{a}, r_{b}\right)=(1 / 2,1 / 2)$ and $\left(r_{a}, r_{b}\right)=(3 / 4,3 / 4)$, respectively. The decrease of the parameter $\mu_{1}$ with the increase of the index $n$, as seen from Table 5, is less significant for the higher stiffness foundation. The effect of the foundation supporting area on the vibration mode of the plate can be seen from Figure 5, where the first mode of the (2-1-2) SSSS plate with $n=0.5$, $a / h=10$, and $\left(k_{1}, k_{2}\right)=(50,50)$ is depicted for various values of $\left(r_{a}, r_{b}\right)$.

The influence of the aspect ratio $a / h$ on the frequency of the plate can be seen from Table 5, where the fundamental frequency parameter $\mu_{1}$ of the SSSS plate increases with the increase of the aspect ratio $a / h$, regardless of the index $n$, the foundation stiffness, and the foundation supporting area. The dependence of the frequency parameter upon the aspect ratio $a / h$ can also be seen from Figure 6, where the length to thickness ratio versus the fundamental frequency parameter of the SSSS and CCCC plates with $n=0.5$ and $n=5$ is shown for $\left(r_{a}, r_{b}\right)=(1 / 4,1 / 4)$ and various values of the foundation stiffness parameters. The effect of the aspect ratio, as seen from the figure, is the most significant for $a / h<20$, and it becomes less significant for $a / h>40$, regardless of the foundation stiffness and boundary condition. The foundation stiffness can change the frequency, but it hardly changes the influence of the aspect ratio on the frequency. 


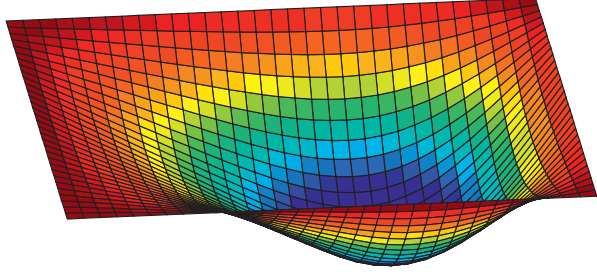

(a)

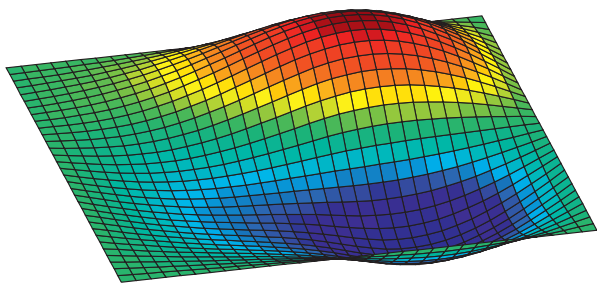

(c)

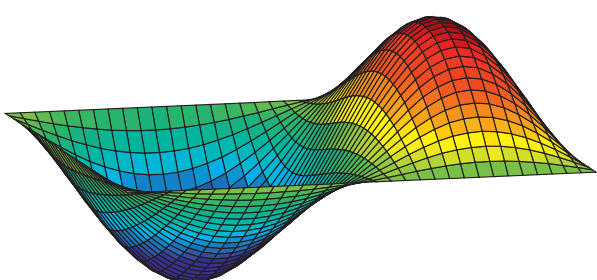

(b)

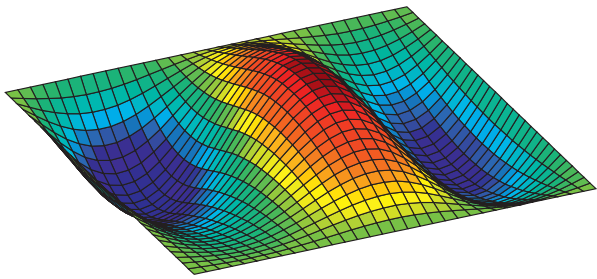

(d)

FIGURE 2: The first four vibration modes of SSSS (2-1-2) plate partially supported by foundation for $n=0.5, a / h=10,\left(r_{a}, r_{b}\right)=(1 / 2,1 / 2)$, and $\left(k_{1}, k_{2}\right)=(50,50)$. (a) 1st mode, $\mu_{1}=2.9155$. (b) 2nd mode, $\mu_{2}=4.9152$. (c) 3rd mode, $\mu_{3}=6.4357$. (d) 4th mode, $\mu_{4}=7.6243$.

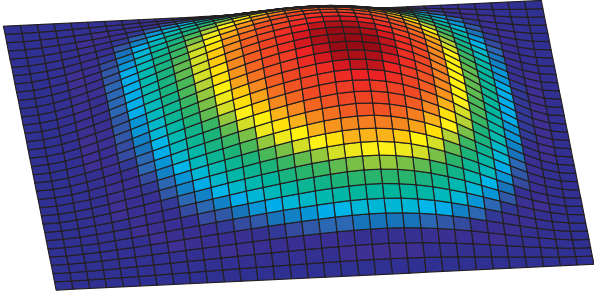

(a)

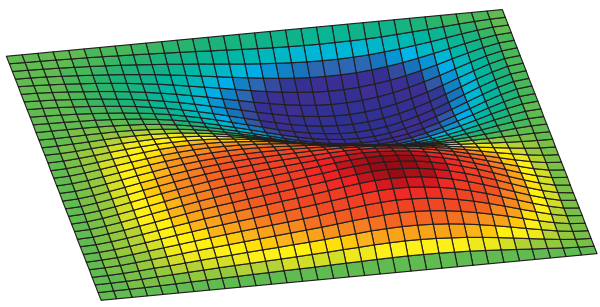

(c)

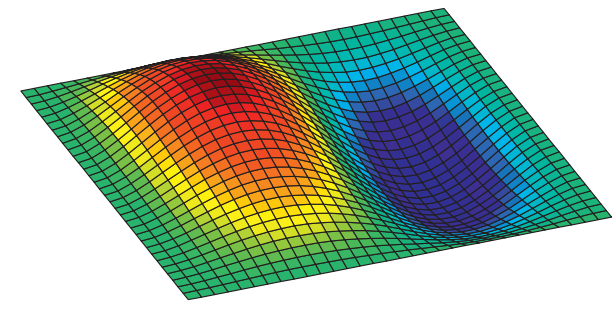

(b)

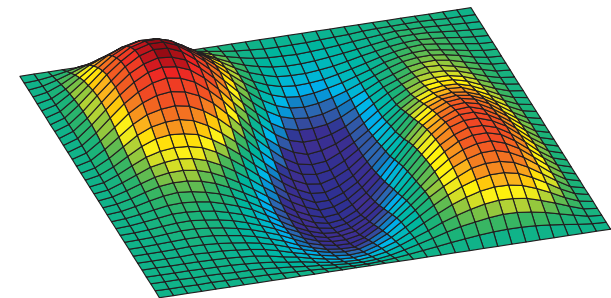

(d)

Figure 3: The first four vibration modes of SCSC (2-1-2) plate partially supported by foundation for $n=0.5, a / h=10,\left(r_{a}, r_{b}\right)=(1 / 2,1 / 2)$, and $\left(k_{1}, k_{2}\right)=(50,50)$. (a) 1 st mode, $\mu_{1}=3.3301$. (b) 2 nd mode, $\mu_{2}=5.7109$. (c) 3 rd mode, $\mu_{3}=6.7229$. (d) 4 th mode, $\mu_{4}=8.7122$.

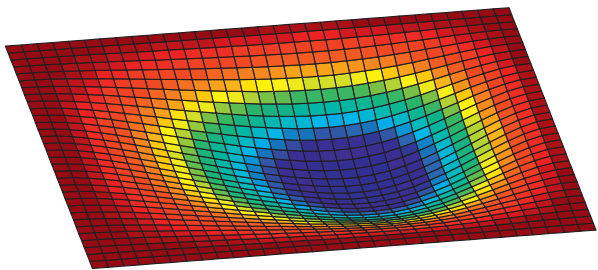

(a)

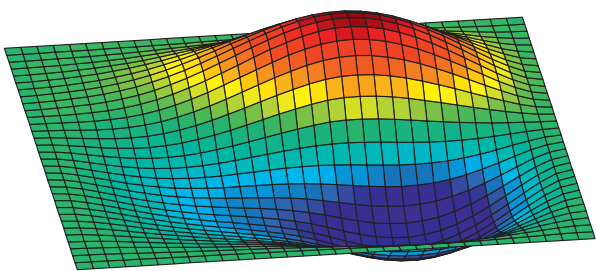

(c)

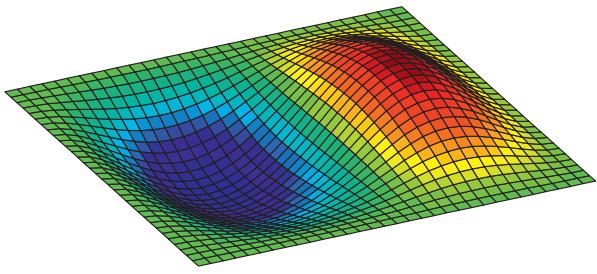

(b)

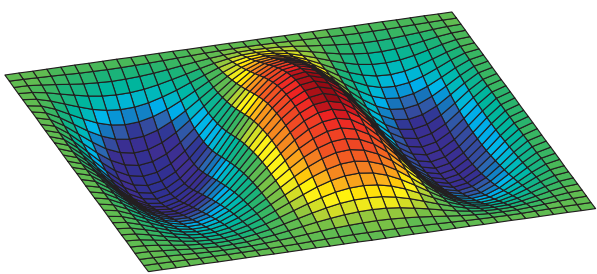

(d)

Figure 4: The first four vibration modes of CCCC (2-1-2) plate partially supported by foundation for $n=0.5, a / h=10,\left(r_{a}, r_{b}\right)=(1 / 2,1 / 2)$, and $\left(k_{1}, k_{2}\right)=(50,50)$. (a) 1st mode, $\mu_{1}=4.2418$. (b) 2nd mode, $\mu_{2}=6.3856$. (c) 3rd mode, $\mu_{3}=8.5778$. (d) 4th mode, $\mu_{4}=9.3137$. 
TABLE 5: Frequency parameter $\mu_{1}$ of (2-1-2) SSSS plate with different foundation supporting areas, foundation stiffness, aspect ratios, and power-law material indices.

\begin{tabular}{|c|c|c|c|c|c|c|c|c|c|}
\hline$a / h$ & $\left(k_{1}, k_{2}\right)$ & $\left(r_{a}, r_{b}\right)$ & Element & $n=0.3$ & $n=0.5$ & $n=1$ & $n=3$ & $n=5$ & $n=10$ \\
\hline \multirow{12}{*}{10} & \multirow{6}{*}{$(10,10)$} & \multirow{2}{*}{$(1 / 4,1 / 4)$} & RFSDT & 2.3428 & 2.1486 & 1.9088 & 1.6797 & 1.6384 & 1.6174 \\
\hline & & & RTSDT & 2.3480 & 2.1541 & 1.9145 & 1.6858 & 1.6448 & 1.6241 \\
\hline & & \multirow{2}{*}{$(1 / 2,1 / 2)$} & RFSDT & 2.5313 & 2.3544 & 2.1406 & 1.9443 & 1.9115 & 1.8968 \\
\hline & & & RTSDT & 2.5362 & 2.3596 & 2.1460 & 1.9503 & 1.9178 & 1.9034 \\
\hline & & \multirow{2}{*}{$(3 / 4,3 / 4)$} & RFSDT & 2.7733 & 2.6162 & 2.4319 & 2.2732 & 2.2503 & 2.2432 \\
\hline & & & RTSDT & 2.7780 & 2.6211 & 2.4371 & 2.2790 & 2.2565 & 2.2497 \\
\hline & \multirow{6}{*}{$(100,100)$} & \multirow{2}{*}{$(1 / 4,1 / 4)$} & RFSDT & 2.5004 & 2.3068 & 2.0651 & 1.8299 & 1.7867 & 1.7645 \\
\hline & & & RTSDT & 2.5071 & 2.3143 & 2.0735 & 1.8398 & 1.7973 & 1.7757 \\
\hline & & \multirow{2}{*}{$(1 / 2,1 / 2)$} & RFSDT & 3.4388 & 3.2516 & 3.0086 & 2.7594 & 2.7131 & 2.6903 \\
\hline & & & RTSDT & 3.4486 & 3.2636 & 3.0237 & 2.7798 & 2.7354 & 2.7144 \\
\hline & & \multirow{2}{*}{$(3 / 4,3 / 4)$} & RFSDT & 4.7366 & 4.6192 & 4.4870 & 4.3912 & 4.3880 & 4.3991 \\
\hline & & & RTSDT & 4.7450 & 4.6290 & 4.4985 & 4.4060 & 4.4042 & 4.4166 \\
\hline \multirow{12}{*}{20} & \multirow{6}{*}{$(10,10)$} & \multirow{2}{*}{$(1 / 4,1 / 4)$} & RFSDT & 2.4137 & 2.2098 & 1.9591 & 1.7215 & 1.6794 & 1.6585 \\
\hline & & & RTSDT & 2.4152 & 2.2114 & 1.9607 & 1.7232 & 1.6811 & 1.6603 \\
\hline & & \multirow{2}{*}{$(1 / 2,1 / 2)$} & RFSDT & 2.6031 & 2.4170 & 2.1931 & 1.9895 & 1.9562 & 1.9419 \\
\hline & & & RTSDT & 2.6045 & 2.4185 & 2.1946 & 1.9912 & 1.9579 & 1.9438 \\
\hline & & \multirow{2}{*}{$(3 / 4,3 / 4)$} & RFSDT & 2.8467 & 2.6810 & 2.4876 & 2.3228 & 2.2996 & 2.2931 \\
\hline & & & RTSDT & 2.8480 & 2.6824 & 2.4890 & 2.3244 & 2.3014 & 2.2950 \\
\hline & \multirow{6}{*}{$(100,100)$} & \multirow[b]{2}{*}{$(1 / 4,1 / 4)$} & RFSDT & 2.5837 & 2.3811 & 2.1292 & 1.8863 & 1.8427 & 1.8212 \\
\hline & & & RTSDT & 2.5856 & 2.3832 & 2.1315 & 1.8890 & 1.8457 & 1.8244 \\
\hline & & \multirow{2}{*}{$(1 / 2,1 / 2)$} & RFSDT & 3.5608 & 3.3679 & 3.1189 & 2.8676 & 2.8230 & 2.8033 \\
\hline & & & RTSDT & 3.5635 & 3.3712 & 3.1231 & 2.8732 & 2.8292 & 2.8101 \\
\hline & & \multirow{2}{*}{$(3 / 4,3 / 4)$} & RFSDT & 4.8738 & 4.7495 & 4.6100 & 4.5121 & 4.5110 & 4.5255 \\
\hline & & & RTSDT & 4.8764 & 4.7525 & 4.6135 & 4.5166 & 4.5159 & 4.5308 \\
\hline \multirow{12}{*}{50} & \multirow{6}{*}{$(10,10)$} & \multirow{2}{*}{$(1 / 4,1 / 4)$} & RFSDT & 2.4352 & 2.2283 & 1.9742 & 1.7340 & 1.6916 & 1.6708 \\
\hline & & & RTSDT & 2.4355 & 2.2285 & 1.9745 & 1.7343 & 1.6919 & 1.6711 \\
\hline & & \multirow{2}{*}{$(1 / 2,1 / 2)$} & RFSDT & 2.6249 & 2.4359 & 2.2089 & 2.0031 & 1.9695 & 1.9554 \\
\hline & & & RTSDT & 2.6252 & 2.4361 & 2.2091 & 2.0033 & 1.9698 & 1.9557 \\
\hline & & \multirow{2}{*}{$(3 / 4,3 / 4)$} & RFSDT & 2.8690 & 2.7006 & 2.5043 & 2.3376 & 2.3144 & 2.3081 \\
\hline & & & RTSDT & 2.8692 & 2.7008 & 2.5046 & 2.3379 & 2.3147 & 2.3085 \\
\hline & \multirow{6}{*}{$(100,100)$} & \multirow{2}{*}{$(1 / 4,1 / 4)$} & RFSDT & 2.6091 & 2.4037 & 2.1486 & 1.9034 & 1.8597 & 1.8385 \\
\hline & & & RTSDT & 2.6094 & 2.4040 & 2.1490 & 1.9038 & 1.8602 & 1.8391 \\
\hline & & \multirow{2}{*}{$(1 / 2,1 / 2)$} & RFSDT & 3.5978 & 3.4032 & 3.1524 & 2.9006 & 2.8567 & 2.8382 \\
\hline & & & RTSDT & 3.5983 & 3.4037 & 3.1531 & 2.9016 & 2.8578 & 2.8393 \\
\hline & & & RFSDT & 4.9168 & 4.7902 & 4.6483 & 4.5496 & 4.5491 & 4.5647 \\
\hline & & $(3 / 4,3 / 4)$ & RTSDT & 4.9172 & 4.7907 & 4.6489 & 4.5503 & 4.5499 & 4.5656 \\
\hline
\end{tabular}

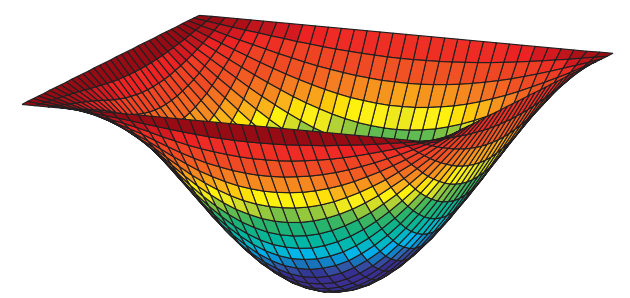

(a)

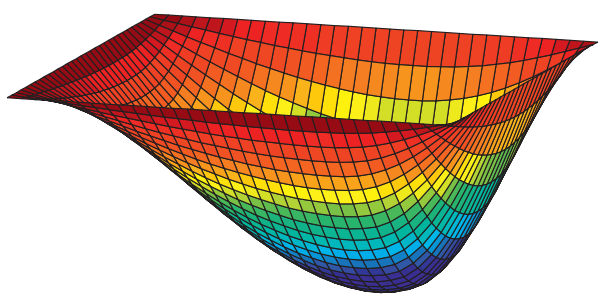

(c)

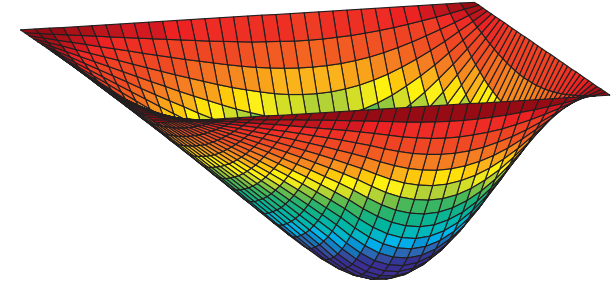

(b)

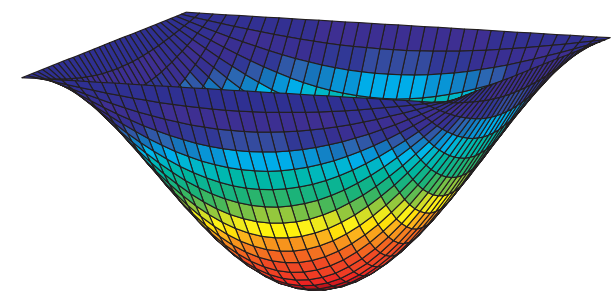

(d)

FIGURE 5: Effect of foundation supporting area on the first vibration mode of (2-1-2) SSSS plate with $n=0.5$, a/h=10, and $\left(k_{1}, k_{2}\right)=(50,50) . \quad$ (a) $\left(r_{a}, r_{b}\right)=(1 / 4,1 / 4), \mu_{1}=2.4980, \quad$ (b) $\left(r_{a}, r_{b}\right)=(1 / 2,1 / 2), \mu_{1}=2.9155, \quad$ (c) $\left(r_{a}, r_{b}\right)=(3 / 4,3 / 4), \mu_{1}=3.7639$, (d) $\left(r_{a}, r_{b}\right)=(1,1), \mu_{1}=5.3462$. 


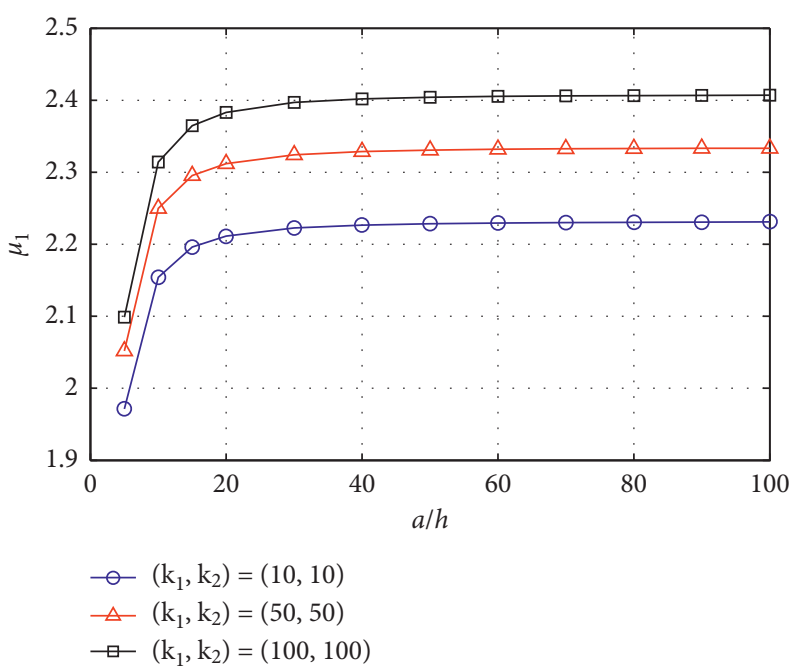

(a)

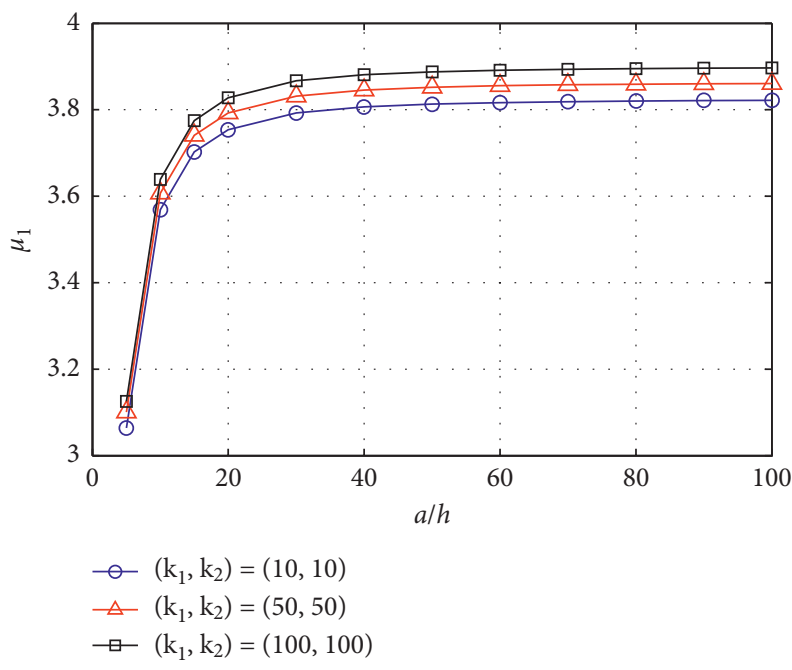

(c)

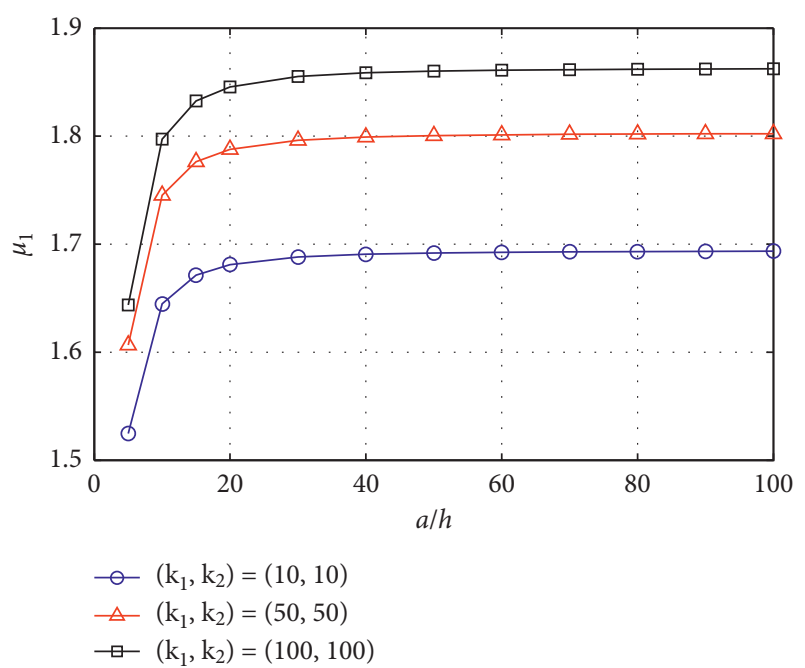

(b)

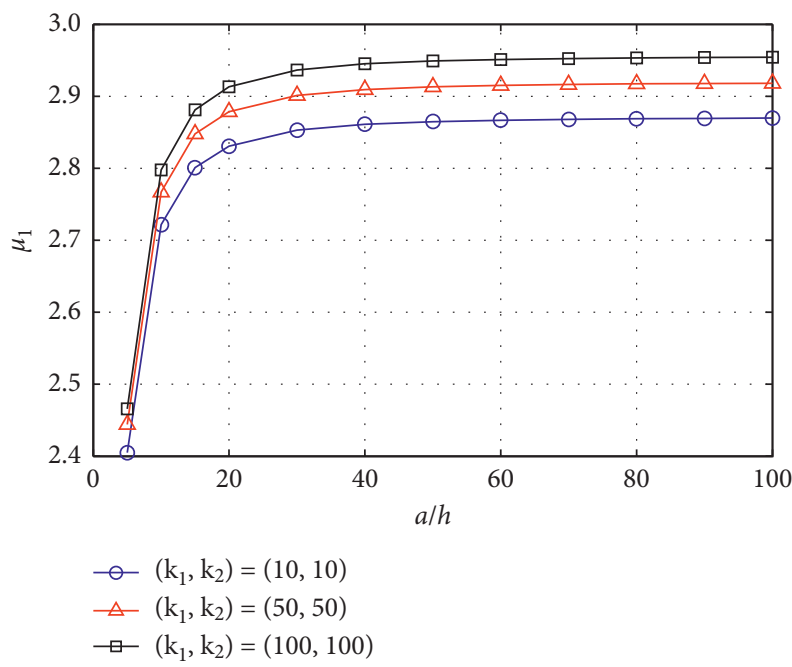

(d)

FIGURE 6: Aspect ratio $a / h$ versus frequency parameter $\mu_{1}$ of SSSS and CCCC plates with $\left(r_{a}, r_{b}\right)=(1 / 4,1 / 4)$ and various foundation stiffness parameters. (a) SSSS plate, $n=0.5$. (b) SSSS plate, $n=5$. (c) CCCC plate, $n=0.5$. (d) CCCC plate, $n=5$.

\section{Conclusions}

The four-unknown RTSDT and RFSDT have been employed to derive quadrilateral finite elements for studying free vibration of FGSW plates partially supported by a Pasternak foundation. The plates consist of three layers, a homogeneous ceramic core and two functionally graded skin layers with material properties varying in the thickness direction by a power graduation law. The elements were derived by using Lagrange and Hermite polynomials to interpolate the in-plane and transverse displacements, respectively. The RFSDT element obtained herein as a special case of the RTSDT element is simple, but it requires the shear correction factor to correct for the discrepancy between the real shear stress distribution and those calculated by the RFSDT. Using the formulated elements, the frequencies and vibration modes have been computed for the plate with various boundary conditions. The effects of the material distribution, foundation stiffness, and foundation supporting area on the vibration behaviour of the plates have been examined in detail. The numerical result reveals that the frequencies obtained by the RTSDT element are slightly higher than that based on the RFSDT element. It has also been shown that the foundation supporting area plays an important role on the vibration characteristics of the plates, and the effect of material distribution on the frequencies is dependent on this factor. The vibration modes of the plates are governed by the foundation supporting area, and the symmetrical modes as seen for the plates fully supported by foundation support can be altered by the partial support. The influence of the layer thickness ratio and the plate aspect ratio on the frequencies was also examined and discussed.

\section{Data Availability}

No data were used to support this study. 


\section{Conflicts of Interest}

The authors declare that they have no conflicts of interest.

\section{Acknowledgments}

The support by Vietnam National Foundation for Science and Technology Development (NAFOSTED) (Grant no. 107.02-2018.23) to the work presented in this article is gratefully acknowledged.

\section{References}

[1] Y. Fukui, "Fundamental investigation of functionally gradient material manufacturing system using centrifugal force," JSME International Journal. Ser. 3, Vibration, Control Engineering, Engineering for Industry, vol. 34, no. 1, pp. 144-148, 1991.

[2] M. Koizumi, "FGM activities in Japan," Composites Part B: Engineering, vol. 28, no. 1-2, pp. 1-4, 1997.

[3] A. M. Zenkour, "A comprehensive analysis of functionally graded sandwich plates: Part 1-deflection and stresses," International Journal of Solids and Structures, vol. 42, no. 18-19, pp. 5224-5242, 2005.

[4] A. M. Zenkour, "A comprehensive analysis of functionally graded sandwich plates: Part 2-buckling and free vibration," International Journal of Solids and Structures, vol. 42, no. 1819, pp. 5243-5258, 2005.

[5] A. M. Zenkour and M. Sobhy, "Thermal buckling of various types of FGM sandwich plates," Composite Structures, vol. 93, no. 1, pp. 93-102, 2010.

[6] S. Xiang, G.-W. Kang, M.-S. Yang, and Y. Zhao, "Natural frequencies of sandwich plate with functionally graded face and homogeneous core," Composite Structures, vol. 96, pp. 226-231, 2013.

[7] A. M. A. Neves, A. J. M. Ferreira, E. Carrera et al., "Static, free vibration and buckling analysis of isotropic and sandwich functionally graded plates using a quasi-3D higher-order shear deformation theory and a meshless technique," Composites Part B: Engineering, vol. 44, no. 1, pp. 657-674, 2013.

[8] H.-T. Thai, T.-K. Nguyen, T. P. Vo, and J. Lee, "Analysis of functionally graded sandwich plates using a new first-order shear deformation theory," European Journal of Mechanics-A/ Solids, vol. 45, pp. 211-225, 2014.

[9] L. Iurlaro, M. Gherlone, and M. Di Sciuva, "Bending and free vibration analysis of functionally graded sandwich plates using the Refined Zigzag theory," Journal of Sandwich Structures \& Materials, vol. 16, no. 6, pp. 669-699, 2014.

[10] S. Pandey and S. Pradyumna, "Analysis of functionally graded sandwich plates using a higher-order layerwise theory," Composites Part B: Engineering, vol. 153, pp. 325-336, 2018.

[11] Z. Belabed, A. A. Bousahla, M. S. A. Houari, A. Tounsi, and S. R. Mahmoud, "A new 3-unknown hyperbolic shear deformation theory for vibration of functionally graded sandwich plate," Earthquakes and Structures, vol. 14, no. 2, pp. 103-115, 2018.

[12] A. A. Daikh and A. M. Zenkour, "Effect of porosity on the bending analysis of various functionally graded sandwich plates," Materials Research Express, vol. 6, no. 6, 2019.

[13] A. Mahmoudi, S. Benyoucef, A. Tounsi, A. Benachour, E. A. A. Bedia, and S. R. Mahmoud, "A refined quasi-3D shear deformation theory for thermo-mechanical behavior of functionally graded sandwich plates on elastic foundations," Journal of Sandwich Structures \& Materials, vol. 21, no. 6, pp. 1906-1929, 2019.
[14] R. D. Mindlin, "Influence of rotatory inertia and shear on flexural motions of isotropic, elastic plates," Journal of Applied Mechanics, vol. 18, pp. 31-38, 1951.

[15] E. Reissner, "Reflections on the theory of elastic plates," Applied Mechanics Reviews, vol. 38, no. 11, pp. 1453-1464, 1985.

[16] J. N. Reddy, "A simple higher-order theory for laminated composite plates," Journal of Applied Mechanics, vol. 51, no. 4, pp. 745-752, 1984.

[17] A. J. M. Ferreira, C. M. C. Roque, and R. M. N. Jorge, "Analysis of composite plates by trigonometric shear deformation theory and multiquadrics," Computers \& Structures, vol. 83, no. 27, pp. 2225-2237, 2005.

[18] M. Aydogdu, "A new shear deformation theory for laminated composite plates," Composite Structures, vol. 89, no. 1, pp. 94-101, 2009.

[19] S. S. Akavci, "Two new hyperbolic shear displacement models for orthotropic laminated composite plates," Mechanics of Composite Materials, vol. 46, no. 2, pp. 215-226, 2010.

[20] J. L. Mantari, A. S. Oktem, and C. Guedes Soares, "A new higher order shear deformation theory for sandwich and composite laminated plates," Composites Part B: Engineering, vol. 43, no. 3, pp. 1489-1499, 2012.

[21] J. L. Mantari, A. S. Oktem, and C. Guedes Soares, "A new trigonometric shear deformation theory for isotropic, laminated composite and sandwich plates," International Journal of Solids and Structures, vol. 49, no. 1, pp. 43-53, 2012.

[22] N. Grover, B. N. Singh, and D. K. Maiti, "Analytical and finite element modeling of laminated composite and sandwich plates: an assessment of a new shear deformation theory for free vibration response," International Journal of Mechanical Sciences, vol. 67, pp. 89-99, 2013.

[23] Y. M. Ghugal and A. S. Sayyad, "A static flexure of thick isotropic plates using trigonometric shear deformation theory," Journal of Solid Mechanics, vol. 2, no. 1, pp. 79-90, 2010.

[24] A. M. A. Neves, A. J. M. Ferreira, E. Carrera et al., "Bending of FGM plates by a sinusoidal plate formulation and collocation with radial basis functions," Mechanics Research Communications, vol. 38, no. 5, pp. 368-371, 2011.

[25] A. M. A. Neves, A. J. M. Ferreira, E. Carrera et al., "A quasi-3D hyperbolic shear deformation theory for the static and free vibration analysis of functionally graded plates," Composite Structures, vol. 94, no. 5, pp. 1814-1825, 2012.

[26] A. M. Zenkour, "Bending of FGM plates by a simplified fourunknown shear and normal deformations theory," International Journal of Applied Mechanics, vol. 5, no. 2, pp. 1-15, 2013.

[27] A. M. Zenkour, "A simple four-unknown refined theory for bending analysis of functionally graded plates," Applied Mathematical Modelling, vol. 37, no. 20-21, pp. 9041-9051, 2013.

[28] R. P. Shimpi and H. G. Patel, "Free vibrations of plate using two variable refined plate theory," Journal of Sound and Vibration, vol. 296, no. 4-5, pp. 979-999, 2006.

[29] H.-T. Thai and S.-E. Kim, "A simple higher-order shear deformation theory for bending and free vibration analysis of functionally graded plates," Composite Structures, vol. 96, pp. 165-173, 2013.

[30] R. P. Shimpi, H. G. Patel, and H. Arya, "New first-order shear deformation plate theories," Journal of Applied Mechanics, vol. 74, no. 3, pp. 523-533, 2006.

[31] H.-T. Thai and T. P. Vo, "A new sinusoidal shear deformation theory for bending, buckling, and vibration of functionally graded plates," Applied Mathematical Modelling, vol. 37, no. 5, pp. 3269-3281, 2013. 
[32] N. E. Meiche, A. Tounsi, N. Ziane, I. Mechab, and E. A. A. Bedia, "New hyperbolic shear deformation theory for buckling and vibration of functionally graded sandwich plate," International Journal of Mechanical Science, vol. 53, no. 4, pp. 237-247, 2011.

[33] T. H. Daouadji, A. Tounsi, and E. A. A. Bedia, "A new higher order shear deformation model for static behavior of functionally graded plates," Advances in Applied Mathematics and Mechanics, vol. 5, no. 3, pp. 351-364, 2013.

[34] A. Bessaim, M. S. Houari, A. Tounsi, S. Mahmoud, and E. A. A. Bedia, "A new higher-order shear and normal deformation theory for the static and free vibration analysis of sandwich plates with functionally graded isotropic face sheets," Journal of Sandwich Structures \& Materials, vol. 15, no. 6, pp. 671-703, 2013.

[35] F. Z. Zaoui, D. Ouinas, and A. Tounsi, "New 2D and quasi-3D shear deformation theories for free vibration of functionally graded plates on elastic foundations," Composites Part B: Engineering, vol. 159, pp. 231-247, 2019.

[36] M. Eisenberger, D. Z. Yankelevsky, and M. A. Adin, "Vibrations of beams fully or partially supported on elastic foundations," Earthquake Engineering \& Structural Dynamics, vol. 13, no. 5, pp. 651-660, 1985.

[37] D. K. Nguyen, "Postbuckling behavior of beams on twoparameter elastic foundation," International Journal of Structural Stability and Dynamics, vol. 4, no. 1, pp. 21-43, 2004.

[38] T. Mori and K. Tanaka, "Average stress in matrix and average elastic energy of materials with misfitting inclusions," Acta Metallurgica, vol. 21, no. 5, pp. 571-574, 1973.

[39] S. S. Rao, The Finite Element Method in Engineering, Elsevier, Amsterdam, Netherlands, 4th edition, 2005.

[40] S. S. Akavci, "Mechanical behavior of functionally graded sandwich plates on elastic foundation," Composites Part B: Engineering, vol. 96, pp. 136-152, 2016. 